\title{
Application of Pert in Reduction of Equipment Procurement Time in a Tertiary Care Teaching Hospital
}

\author{
Dr.D.N.Suharsh, Dr.N.LakshmiBhaskar, Dr.P.S.RakeshPrabhu,Dr.N.Rakesh. \\ Dept. of Hospital Administration, NIMS.
}

\begin{abstract}
Equipment procurement is a necessity of any multi/super speciality hospital. It is often associated with tedious and laborious procedures the following of which is mandatory in any purchase. This is especially important in a public sector institute where every purchase is scrutinized. These procedures often lead to delayed procurement which ultimately compromises the care provided to the patients. This study lists the various steps that need to be followed in procurement of equipment taking the example of MRI machine procurement at a tertiary care teaching hospital. It lists the delays that were encountered in the procurement of the MRI machine and also the ways in which these delays could be overcome by application of PERT in the procurement process.
\end{abstract}

Keywords: Hospital equipment, tendering process, procurement delays, PERT.

\section{Introduction}

The procurement of any equipment is started with the decision to procure the equipment and starting with the tendering process. The tendering process needs to be followed for any purchase made by a public enterprise as per the guidelines of the Central Vigilance Commission (CVC) to maintain transparency in any transaction. This process also gives fair opportunity to the various players in the market to compete without showing any favorability to any particular company.

The following are the various steps that are followed in the tendering process:-

Decision to purchase(Name of equipment\& quantity required) $\rightarrow$ Constitution of Specification committee $\rightarrow$ Tender Notification $\rightarrow$ News paper notification and publicity of tender $\rightarrow$ Last date for submission of bids $\rightarrow$ Listing out bids received $\rightarrow$ Constitution of Technical committee $\rightarrow$ Release of Technical Evaluation Report $\rightarrow$ Price bid opening and constitution of Price bid opening committee $\rightarrow$ Finalization of supplier $\rightarrow$ Release of Purchase Order.

\section{Methods}

\subsection{Setting}

Nizams Institute of Medical Sciences (NIMS) is a 1200 bedded Tertiary care teaching Hospital catering to the population of the states of Telangana, Andhra Pradesh and also neighbouring states of Karnataka \& Maharashtra. It is a premiere autonomous institute providing super specialty services and also a few broad specialties. It runs on a self sustaining model with partial funding from the Government of Telangana. Being a public institute it has to follow the government guidelines of procurement through tendering process.

\subsection{Procedure being followed}

Tendering process being followed at NIMS:-

- Name and quantity of the required item are requisitioned by the head of the concerned department.

- A specification committee is constituted by the director to meet and discuss the requirement of the specific equipment and also to reach a concenses regarding the best suited specifications for the requisitioned item.

- Tender notification is published in reputed newspapers apart from putting up in website of NIMS and also by intimating vendors through post and e-mail. To clarify any doubts of vendors a pre-bid meeting can also be constituted.

- After the completion of bidding period the bids are opened and are shortlisted for further evaluation.

- Further evaluation usually occurs in two stages.

\section{1) Technical Evaluation}

2) Price bid

In technical evaluation an expert committee constituted by the director examine the bids received and select only those bids which meet the specifications specified earlier.

In price bid the lowest quoted bid for the requisitioned item is selected for award of contract. 
- $\quad$ The three lowest bids are taken as L1, L2 and L3.

- Negotiations are done with L1 before a final price is decided and the contract is signed.

\subsection{MRI Procurement}

NIMS being a tertiary care hospital requires round the clock investigation facilities of which MRI is also a part. Majority of cases requiring MRI are from the Neurology and Neurosurgery Departments with other departments requiring MRI based on the need of the patient.The following procedure occurred in the procurement of MRI in NIMS:-

$>$ The decision to purchase MRI was taken on 6546813

$>$ After 1 week the specification committee was constituted to list out the specifications required in the MRI machine to be procured.

$>$ It took 1month for the specification committee to convene and come out with the tender notification.

$>$ Six weeks time was given for tender applicants.

$>$ It took 10 weeks for the constitution of technical committee and evaluation of the bids received.

$>$ It took 2 weeks for the opening of price bids and further 4 weeks for the conduct of negotiations with the lowest bidder to finalize the tender recipient.

$>$ The purchase order was received further after 2 weeks.

$>$ It took 4 months for the receiving of equipment. However on arrival it was found that the entry was too small for the passage of equipment.

$>$ The equipment had to be put in storage and the wall of the room housing the equipment had to be brought down, the equipment taken inside and later closed again. Also the electrical wiring had to be redone to suit the equipment. This took another 10 weeks.

$>$ No manpower to run the MRI machine was trained during the period of installation of the equipment and it took further 10 weeks to recruit and train the manpower required to man the equipment.

Overall it took around 65 weeks for the procurement, installation and running of the MRI machine.

\subsection{Application of PERT}

The program (or project) evaluation and review technique, commonly abbreviated PERT, is a statistical tool, used in project management, is designed to analyze and represent the tasks involved in completing a given project.

\section{The various steps employed in application of PERT to a project are:-}

* Identification of specific activities and milestones.

* Determine the proper sequence of activities.

* Construct a network diagram.

* Estimate time required for each activity.

* Determine the critical path.

* Update PERT chart as the project progresses.

Determination of critical path:-It is determined by adding the times for the activities in each sequence and determining the longest path in the project.Critical path determines the total calendar time required for the project.The amount of time a non-critical path activity can be delayed without delaying the project is referred to as slack time.

By applying PERT a network diagram is constructed depicting all the activities involved in the procurement of the MRI machine with the intervening arrows depicting the time taken for the completion of each of these steps. Upon completion of the network diagram the path requiring the maximum time is the critical path and any measures taken to reduce the time taken for activities in this path will help in reducing the project completion time. 


\section{Results}

Network chart based on PERT is as follows

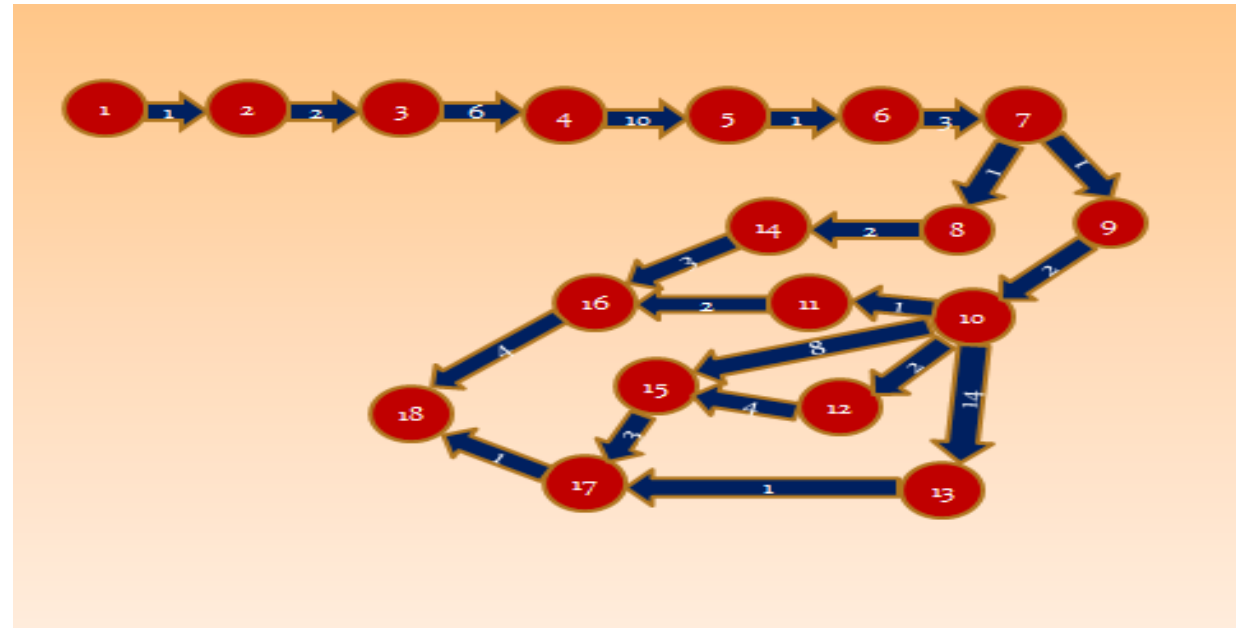

Numbers in arrows indicate the time in weeks for the completion of task.

Numbered circles indicate the following activities:-

1.Decision to purchase MRI2.Specification committee

3. Tender notification

4.Technical evaluation

5. Price bid

6.Negotiations

7. Selection of tender recipient

8.Staffing

9. Purchase order

10.Starting of construction works

11. Department of radiology

12.Completion of electrical works

13. Receiving of equipment

14. Staffing(recruitment)

15. Completion of civil works

16. Training of staff

17. Operational use of MRI

By application of PERT the total procurement time (Critical Path Time) is around 42 weeks.

\section{Discussion}

Utilizing PERT all the activities required for the purchase of equipment can be planned before hand as a result of which multiple activities which can be done simultaneously can be planned beforehand thereby reducing the time of completion of overall project. Here in the purchase of MRI equipment by the application of PERT from the initial decision making stage the time required for the final procurement of the equipment can be brought down to about 42 weeks which is a considerable reduction of around 23 weeks.

Also if further steps are taken to see that the time required for the activities in the critical path (here $1 \rightarrow 2 \rightarrow 3 \rightarrow 4 \rightarrow 5 \rightarrow 6 \rightarrow 7 \rightarrow 9 \rightarrow 10 \rightarrow 13 \rightarrow 17 \rightarrow 18$ ) are brought down the project completion rate can be further brought down. Prior planning will also help in early convening of committees thereby reducing the time required for selection of tender recipient. By lacking proper planning the equipment even after arrival had to be stored as the civil structure was not compatible for the placement of the machine. The room housing the equipment had to be rebuilt along with the electrical wiring. Also the man power required to run the machine had to be trained only after the machine was installed leading to further delay. Had PERT been employed all these steps could be planned beforehand and the time for completion of these works from issue of purchase order to the running of the machine could be reduced from 36 weeks to 18 weeks.

\section{Conclusion}

By applying PERT in the planning stage of procurement of any equipment all the steps required in the procurement of the equipment can be enumerated and once the network diagram is completed all the activities can proceed simultaneously along with the activities of the critical path, thereby completing the project within the specified timeframe without any delay. Also the project can be hastened by reducing the time taken for completion of activities in the critical path. 